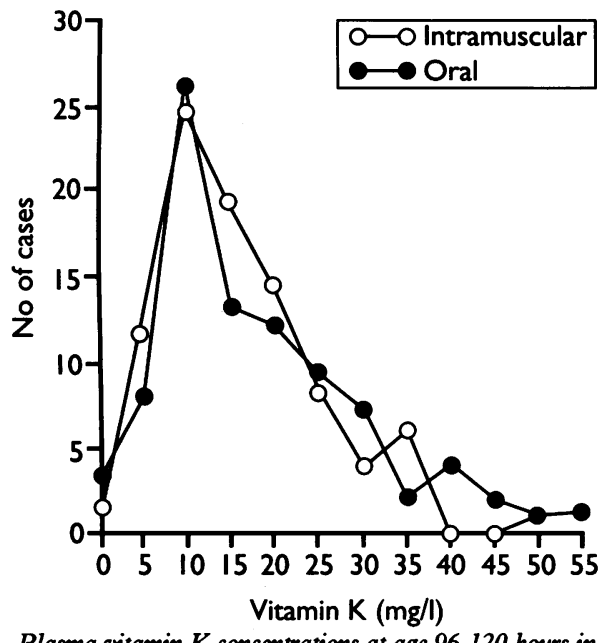

Plasma vitamin $K$ concentrations at age $96-120$ hours in 88 infants given $1 \mathrm{mg}$ vitamin $K$ intramuscularly and in 88 given 2 mg orally

significant difference in the mean vitamin $\mathrm{K}$ concentrations between the groups ( $t$ test), and the distributions of the concentrations were similar. None of these patients developed late haemorrhagic disease of the newborn.

These results suggest that a larger dose of vitamin $\mathrm{K}$ is needed for oral administration than for intramuscular administration to maintain similar plasma vitamin $\mathrm{K}$ concentrations at 97-120 hours. Follow up studies are needed to establish whether $2 \mathrm{mg}$ vitamin $\mathrm{K}$ given orally at birth is as effective prophylaxis as $1 \mathrm{mg}$ given intramuscularly.

School of Paediatrics, University of New South Wales, Royal Hospital for Women, Paddington,

New South Wales 2021

Australia

M GUPTA

School of Pathology,

University of New South Wales

D NAIDOO

1 Golding J, Greenwood R, Birmingham K, Mott M. Childhood cancer, intramuscular vitamin $K$, and pethidine given during cancer, intramuscular vitamin
labour. $B M \mathcal{F}$ 1992;305:341-6.

2 McNinch AW, Tripp JH. Haemorrhagic disease of the newborn in the British Isles: two year prospective study. BMF 1991;303: in the B

\section{Informed consent}

EDITOR,-One factor not apparently considered explicitly by Christine Lavell-Jones and colleagues, which may well affect the quality of informed consent, was the intelligibility of the information that they gave to patients. ${ }^{1}$ The example given in their paper, of an operation information card for cholecystectomy, contained six items of information. Analysis of this text indicates a Flesch reading ease score of $58 .^{2}$ This score corresponds to a fairly difficult style, requiring an above average educational attainment for comprehension and intelligible to only about $40 \%$ of adults. ${ }^{2}$ No details were given of the language used by the house officer in explaining operations. If this was as complex as the written information in the example it is not surprising that the patients' recall of information was poor.

Guidance on making communications with patients intelligible to most of the adult population has been available for many years and has recently been summarised. ${ }^{3}$ Some groups are now putting this advice into practice.

DAVID WILLIAMS

Regional Medical Physics Department,

Sunderland District General Hospital

Sunderland SR4 7TP

1 Lavell-Jones C, Byrne DJ, Rice P, Cuschieri A. Factors affecting quality of informed consent. BMF 1993;306:885-90. (3 April.)
2 Miller GA. Language and communication. New York: McGrawHill, 1963:131-9.

3 Ley P. Communicating with patients. London: Croom Helm,

4 Clarke SEM, McKillop JH, Prescott MC, Williams ED Information for patients and staff concerning nuclear medicine. Nucl Med Commun 1992;13:271-8.

\section{SHO training}

\section{Juniors need time to learn}

EDrToR,-Maureen Baker makes some pertinent comments regarding the educational content of junior doctors' posts, particularly senior house officer posts. ${ }^{1}$ Recently I conducted a survey of the educational content of registrar posts in general and geriatric medicine in the North West region.

In all, 53 of 79 subjects $(67 \%)$ responded to the questionnaire, which asked about study days, study time, ability to attend hospital and departmental meetings, and whether study leave was granted. Only four (8\%) had an official study day and $13(25 \%)$ a half day. Of those responding, 14 (26\%) were allowed study time but $37(70 \%)$ rarely or never had any time for study. Educational opportunities often only occur during lunchtime meetings, but $16(30 \%)$ could attend these only occasionally because of their service commitments. An appreciable minority (four, $\mathbf{8 \%}$ ) was unable to take study leave.

Many registrars have their MRCP and increasingly require research experience before being appointed to a senior registrar post. Unfortunately, $30(57 \%)$ of those responding were not given any encouragement to partake in research.

The North West region is probably typical of other regions; therefore the commitment of some people to training needs to be questioned. In an attempt to get round this difficult problem the North West region has incorporated all medical registrar posts into rotations and is in the process of organising a mentor scheme on a regional basis. An example for others to follow?

DAVID G SMITHARD

Elderly Care Unit,

St Thomas's Hospital,

London SEl 7EH

1 Baker M. Enhancing the educational content of SHO posts. $B M \mathcal{J}$ 1993;306:808-9. (27 March.)

\section{Consultants need time to teach}

EDITOR,-Maureen Baker identifies the need to enhance the educational content of senior house officers' training,' but increasing standards will need more consultant input, and she does not say how time for this may be found.

A common media view is that consultants' days are dominated by golf and private practice. The reality is different. Most give a high service commitment and work long hours. The requirement for greater management roles in the form of clinical directorates, the development of medica audit, and the introduction of trusts wishing to see "value for money" from staff have all resulted in increased demands on consultants' time. The reduction of junior doctors' hours, an admirable objective, is adding to the pressure on senior staff. Moves to shorten the duration of training will require this to become more intensive and, as Baker has identified, will mean greater consultant commitment. Where is the time to provide this?

There is an established clinical tutor system, and the royal colleges have been developing their system of regional advisers and college tutors. However, these posts are taken on in addition to clinical workloads and many capable individuals will not consider undertaking them because of the time required. Important as these roles are, they are barely scratching the surface of what is needed. Crucial steps are the recognition and acceptance that more time will need to be identified for education. Only then can our existing staffing structure be modified so that all consultants with junior staff can allocate appropriate time for their training roles.

I believe that the most effective way to achieve this would be by creating additional consultant posts with specific responsibility for education. These must be clinical posts in the individual specialities. Such posts could be filled by new appointees or established consultants wishing to assume a greater role in education. For instance, creating an additional post (half educational and half clinical) could have two important effects. The educational sessions would be devoted to taking a lead role in that speciality, and indeed in many cases the individual could become college tutor. The clinical sessions, if truly additional, could release time from other consultant staff for their educational responsibilities. Controls would be needed to ensure that educational time did not become compromised by other demands, but there are means of achieving this.

Training in the United Kingdom has produced consultants of high quality but often after inappropriately long training periods. The Department of Health wishes to shorten training time. If the quality of training is to be at least maintained, and hopefully improved, changes will be needed to allow for increased consultant input.

TONY COAKLEY

Kent Postgraduate Medical Centre

Kent and Canterbury Hospital,

Canterbury CT1 3NG

1 Baker $M$. Enhancing the educational content of SHO posts. $B M \mathcal{F}$ 1993;306:808-9. (27 March.)

\section{Assessment initiative in accident and emergency}

EDITOR,-Maureen Baker highlights many of the problems encountered in the training of senior house officers and suggests ways in which it could be improved. ${ }^{1}$ For many years senior house officers in accident and emergency have received some form of regular formal teaching in most departments, but the assessment of the senior house officers and their training is not formalised in many departments.

We have recently changed our method of assessing senior house officers working in a large acciden and emergency department in an attempt to solve some of these problems. Previously the assessment in our department consisted of a structured discussion with one of the consultant medical staff. This interview included subjective assessments of performance and career counselling as appropriate and provided an opportunity for the senior house officer to raise problems on a one to one basis. We have augmented this interview with an objective structured clinical examination, including a projected slide examination. This assessment is carried out after one month and then repeated at the end of the fifth month of the six month post. We have identified a core of knowledge and practical skills that we consider to be vital components of training in accident and emergency medicine and to be the syllabus for testing.

The initial objective structured clinical examination consists of skill stations testing basic life support, intubation, the management of cardiac arrest, and a simple dressing procedure such as the application of a broad arm sling. There are also stations for interpreting data assessing electrocardiographs, making calculations in particular cases (for example, the Glasgow coma score, toxic dose of local anaesthetic, and fluid requirements in patients with burns), and interpreting radiographs. The second objective structured clinical examination repeats some of these skill stations but includes others, such as central venous access, insertion of intraosseous needles, advanced airway care, and counselling of patients with certain injuries. 